\title{
PENGGUNAAN PEMBELAJARAN 4.0 BERBANTUAN APLIKASI GOOGLE CLASSROOM DAN GOOGLE FORM DALAM MATA KULIAH ILMU SOSIAL BUDAYA DASAR
}

\subsection{LEARNING USING GOOGLE CLASSROOM APPLICATION AND GOOGLE FORM ON BASIC SOCIAL AND CULTURE SUBJECT}

\author{
Desy Irsalina Savitri ${ }^{1)}$ \\ 1) Fakultas Keguruan dan Ilmu Pendidikan \\ Universitas Borneo Tarakan \\ Jalan Amal Lama Nomor 1, Tarakan \\ Email: ${ }^{1}$ desy.irsalinasavitri@gmail.com
}

\begin{abstract}
ABSTRAK
Era globalisasi sudah lama didengungkan di Indonesia, globalisasi IPTEK sudah hampir menyebar di Indonesia bahkan di pulau yang jauh dari pusat pengembangan di ibu kota provinsi misalnya di Tarakan Kalimantan Utara. Begitu pula dengan kemajuan teknologi, kemajuan teknologi selalu dikaitkan dengan globalisasi. Tidak dapat dipungkiri bahwa perkembanggan teknologi tidak dapat dihindarkan dari kehidupan manusia bahkan di Kota Tarakan. Hal tersebut juga dikaitankan dengan pembangunan SDM terhadap relevansi pada dunia pekerjaan. Semua tenaga pendidik perlu menyiapkan Peserta didik yang siap dalam berkompetitif dalam kehidupan dan pendidikan. Peserta didik, dalam hal ini mahasiswa sudah disiapkan untuk mengenal teknologi. Pada artikel kali ini peneliti menerapkan pembelajaran 4.0 kepada mahasiswa Fakultas Keguruan dan Ilmu Pendidikan Universitas Borneo Tarakan dalam mata kulian Ilmu Sosial Budaya Dasar untuk mengetahui kebermanfaatan pembelajaran kepada mahasiswa Universitas Borneo Tarakan. Penelitian ini menggunakan pembelajaran jarak jauh 4.0 yang dapat dilaksanakan dimana saja tanpa batasan ruangg kelas dengan bantuan aplikasi google classroom. Untuk mengetahui efektifitas pembelajaran peneliti menggunakan tes tulis dengan bantuan aplikasi google form. Hasil penelitian dari 3 kelas yang berbeda menggunakan aplikasi google form menunjukkan bahwa terdapat perbedaan signifikan. Kelas A dan B mengalami hasil yang dapat dikatakan kurang memuaskan yaitu di tingkat rata-rata angka $66-69 \%$. Sedanggkan kelas C memiliki nilai rata-rata $76,77 \%$.
\end{abstract}

Kata Kunci : Pembelajaran 4.0, Google Clasroom, Google Form

\begin{abstract}
The era of globalization has long been echoed in Indonesia. Globalization of science and technology has almost spread in Indonesia even to the entire archipelago, for instance in Tarakan, North Kalimantan. Likewise with technological progress, technological progress has always been associated with globalization. It is undeniable that technology development cannot be avoided from human life even in Tarakan City. This is also related to the development of human resources to the relevance of the world of work. All educators need to prepare students who are ready to be competitive in life and education. College students have been prepared to get to know technology. In this article the researcher applies 4.0 learning to the students of the Faculty of Teacher Training and Education of the Borneo University of Tarakan in the field of Basic Social and Culture Sciences to find out the usefulness of learning to students of Borneo University of Tarakan. This study uses 4.0 distance learning that can be carried out anywhere without classroom limitations with the help of the google classroom application. To find out the effectiveness of learning researchers used a written test by the google form application. The results of research from 3 different classes using the google form application indicate that there are significant differences. Class $A$ and $B$ experience results that can be said to be less satisfactory, namely at the average level of $66-69 \%$. While $C$ class has an average value of $76.77 \%$.
\end{abstract}

Keywords: 4.0 Learning, Google Clasroom, Google Form 


\section{PENDAHULUAN}

Teknologi selalu mengalami perubahan dan perkembangan pada setiap jaman. Teknologi berkembang karena adanya manusia. Keberadaan manusia dan teknologi tidak dapat dipisahkan, kedua faktor tersebut pasti saling berkaitan. Perkembangan teknologi dipengaruhi oleh manusia, sebaliknya manusia juga dipengaruhi oleh perkembangan teknologi. Saat ini berada pada perkembangan era globalisasi yang hampir menyeluruh disetiap poros dunia. Maka siapa yang tidak mampu mengkuti arus perkembangan teknologi dengan baik akan tergilas oleh jaman.

Indonesia negara yang memiliki banyak pulau yang tersebar atas berbagai macam manusia. Merupakan bentuk tantangan tersendiri dalam mengikuti perkembangan jaman. Terutama dalam mengembangkan sumber daya manusianya. Kualitas sumber daya manusia memengaruhi kualitas daya kompetisi di dalam masyarakat.

Pulau Kalimantan merupakan salah satu pulau besar di Indonesia, namun hingga saat ini pendidikan dan perkembangan sumber daya manusianya belum mampu berkembang secara maksimal. Masih terdapat pendidikan belum merata. Misalnya hasil dari upaya pengembangan pendidikan di Kalimantan Tengah berbeda dengan di Kalimantan Utara. Namun sebenarnya ranah pendidikan dapat diberikan dan dikembangkan dimana saja. Hanya saja dari faktor tenaga pendidik diharapkan untuk lebih kreatif menggembangkan sistem pendidikan sesuai dengan keunikan masing-masing daerah. Saat ini jaringan internet sangat menjamur di semua kalangan dan semua usia di masyarakat. Maka pendidik perlu mendayaggunakan internet sebagai cara mentransfer ilmu penggetahuan.

Perlu diingat bahwa terdapat berbagai cara dalam menerapkan proses pembelajaran, salah satunya pembelajaran 4.0 yang memanfaatkan jaringan internet. Pembelajaran 4.0 di lingkup pendidikan perguruan tinggi merupakan salah satu upaya grand desain dari pemerintah untuk meningkatkan daya saing mahasiswa sebagai bekal awal meningkatkan sumber daya manusia. Selanjutnya tinggal bagaimana upaya dari tenaga pendidiknya menerapkan dan mengembangkan usaha tersebut.

Pembelajaran 4.0 merupakan bentuk penerapan pembelajaran yang memanfaatkan perkembangan teknologi dengan berbantuan aplikasi google classroom dan google form.

Albantani dan Rozak (2018) google classroom sebuah aplikasi yang dirancang untuk mempermudah interaksi antara pendidik dengan peserta didiknya dalam dunia maya. Aplikasi ini memberikan kesempatan kepada para pendidik untuk memperdalam bidang keilmuan yang ingin dimilikinya kepada peserta didik. Tenaga pendidik memliki peran sebagai fasilitator dan memiliki keleluasaan waktu untuk membagikan kajian keilmuan dan memberikan tugas mandiri kepada mahasiswa. Selain itu, pendidik juga dapat membuka ruang diskusi bagi para peserta didik secara online. Namun demikian, terdapat syarat pasti dalam mengaplikasikan google classroom yaitu membutuhkan akses internet.

Putri (2017) memaparkan bahwa kegiatan pembelajaran merupakan proses mentrasnferkan pesan pembelajaran berupa materi belajar dari sumber belajar kepada peserta didik salah satunya menggunakan google classroom. Google Classroom ini dapat menghubungkan dosen dan mahasiswa secara digital. Aplikasi terbaru Google ini selain dapat diakses di PC juga dapat diakses melalui ponsel dan tablet berbasis android dan iOS. Salah satu kecanggihan dari aplikasi ini adalah dapat digunakan secara bersama-sama dalam kelompok.

Shaharanee, dkk (2017) said online education continues to grow and is playing and increasingly significant role in Malaysian higher education. On the context of integration of Google classroom into the teaching and learning of data mining and related applications concepts, the users (teachers or students) must have perceptions that Google classroom is useful in helping in the teaching and learning process, as its ease of use they will intend to use it when needs arise. 
Paparan tersebut menjelaskan bahwa pembelajaran mengggunakan alat komunikasi google classroom dapat membantu pendidik dan peserta didik melalui sebuah PC yang membutuhkan jaringan internet, namun dapat diakses dalam kelompok dalam waktu bersamaan di tempat yang berbeda-beda.

\section{METODE PENELITIAN}

Penelitian ini merupakan penelitian kualitatif dengan rancangan penelitian studi kasus. Mertler (2011) menyatakan bahwa penelitian kualitatif merupakan penelitian yang luas dan holistik terhadap pengumpulan data. Rancangan kualitatif 'menggunakan observasi sistematis agar bisa memeroleh ilmu pengetahuan, dan menjawab pertanyaan yang sedang diteliti tanpa dapat memanipulasi data, karena peneliti hanya mengambil data sesuai hasil pengamatan dan pengambilan data lapang. Subjek dalam penelitian ini adalah Mahasiswa Biologi kelas A, B, dan C Universitas Borneo Tarakan. Instrumen yang digunakan dalam penelitian ini adalah lembar kerja dalam bentuk google form dan dokumen rekap dari google classroom. Instrument ini digunakan untuk penumpulan data. Data yang dikumpulkan adalah data tentang pemanfaatan google classroom.

Tekik penumpulan data melalui track rekap google classroom dan analisis hasil kerja mahasiswa melalui google classroom. Teknik pengumpulan data untuk memperkuat data dari google classroom.

\section{HASIL DAN PEMBAHASAN}

Penerapan pembelajaran 4.0 berbantuan aplikasi google classroom dan google form. Pelaksanaan penelitian ini dilakukan selama 15 kali pertemuan MK dari bulan SeptemberNovember 2018 dan dilaksanakan di Universitas Borneo Tarakan kepada mahasiswa Biologi anggkatan 2017. Pembelajaran yang sebenarnya sebanyak 14 kali pertemuan tidak selalu di dalam kelas. Sebanyak 5 kali pertemuan pendidik menggunakan aplikasi google classroom. Di ruang online itulah mahasiswa diberi kesempatan untuk diskusi bersama walaupun tidak berada di dalam satu ruangan yang sama.
Karena jadwal dari ketiga kelas tersebut beruntutan pada hari yang sama maka dosen lebih mudah mengorganisasikan materi dalam pembelajaran. Dosen sebagai pendidik hanya memberi umpan materi berupa topik terupdate terkait sosial dan budaya kepada mahasiswa untuk kemudian menjadi bahan diskusi di dalam ruang online. Dosen dapat memanfaatkan pembelajaran online dan mudahkan untuk menilai keaktifan mahasiswa. Dosen dapat memantau dan memberi nilai plus kepada mahasiswa yang saat itu memberi tanggapan. Ini juga dapat membantu mahasiswa yang malu mengungkapkan pendapat di depan kelas.

Berdasarkan hasil tersebut sistem pembelajaran 4.0 berjalan dengan baik di kelas $C$, sedangkan di kelas A dan B tidak berjalan baik karena keterbatasan jaringggan paketan internet dari mahasiswa, sehingga informasi tidak tersebar secara maksimal.

Pada penelitian ini peneliti hanya memaparkan sebatas pada jumlah poin nilai pada setiap butir soal dan nilai rata-rata yang didapatkan oleh mahasiswa kelas A, B, dan C dalam mata kuliah Ilmu Sosial Budaya Dasar beserta kelemahan dari penggunaan google classroom pada saat pembelajaran.

Memang benar penggunaan internet sudah menjamur di kalangan masyarakat indonesia dari semua kalangan usia dan strata sosial. Namun perlu diingat bahwa setiap penggunaan model pembelajaran pasti terdapat kelemahankelemahannya masing-masing.

Kelemahan yang terdapat pada aplikasi ini adalah frekuensi jaringan internet yang terkadang melambat. Terutama di Tarakan pada saat hujan datang, ferkuensi jaringgan internet melambat sehingga sulit mengakses internet dengan cepat. Pun saat peneliti melakukan pembelajaran saat itu terjadi berbagai gempa yang merusak beberapa fasilitas di Indonesia yang membuat keterlambatan frekuensi akses satelit jaringan internet.

Hal tersebut terlihat dari analisis kemampuan mahasiswa pada saat pengerjaan lembar kerja analisis melalui google form. Berdasarkan hasil pengumpulan data Mahasiswa yang kelasnya 
JURNAL BORNEO SAINTEK

Volume 2, Nomor 1, April 2019

e-ISSN 2599-3313

p-ISSN 2615-434X

mengikuti prosedur dan instruksi dosen memiliki daya analisis yang baik. Hal tersebut
Available online at www.jurnal.borneo.ac.id

Halaman 20-25

dapat terlihat dari tabel analisis masing-masing soal.

Tabel 1. Soal 1

\begin{tabular}{lccc}
\hline Scor & Kelas A & Kelas B & Kelas C \\
\hline $\mathbf{5 - 1 0}$ & 6 & 14 & 3 \\
\hline $\mathbf{1 1 - 1 5}$ & 24 & 19 & 17 \\
\hline $\mathbf{1 5 - 2 0}$ & 5 & 2 & 12 \\
\hline TOTAL & 35 & 35 & 32
\end{tabular}

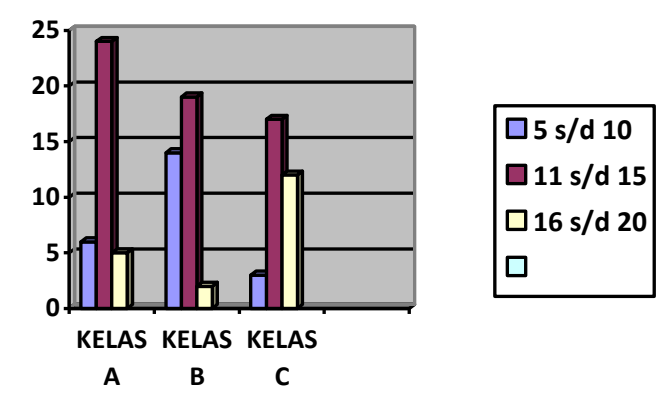

Gambar 1. Grafik Soal 1

Tabel 2. Soal 2

\begin{tabular}{lccc}
\hline Scor & Kelas A & Kelas B & Kelas C \\
\hline $\mathbf{5 - 1 0}$ & 1 & 2 & 3 \\
\hline $\mathbf{1 1 - 1 5}$ & 27 & 32 & 16 \\
\hline $\mathbf{1 5 - 2 0}$ & 7 & 1 & 13 \\
\hline Total & 35 & 35 & 32 \\
\hline
\end{tabular}

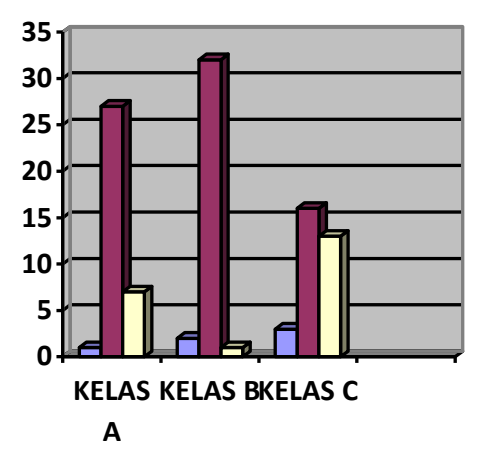

Gambar 2. Grafik Soal 2

Tabel 3. Soal 3

\begin{tabular}{cccc}
\hline Scor & Kelas A & Kelas B & Kelas C \\
\hline $\mathbf{5 - 1 0}$ & 13 & 9 & 12 \\
\hline $\mathbf{1 1 - 1 5}$ & 17 & 29 & 12 \\
\hline $\mathbf{1 5 - 2 0}$ & 5 & 7 & 8 \\
\hline TOTAL & 35 & 35 & 32 \\
\hline
\end{tabular}


JURNAL BORNEO SAINTEK

Volume 2, Nomor 1, April 2019

e-ISSN 2599-3313

p-ISSN 2615-434X
Available online at www.jurnal.borneo.ac.id

Halaman 20-25

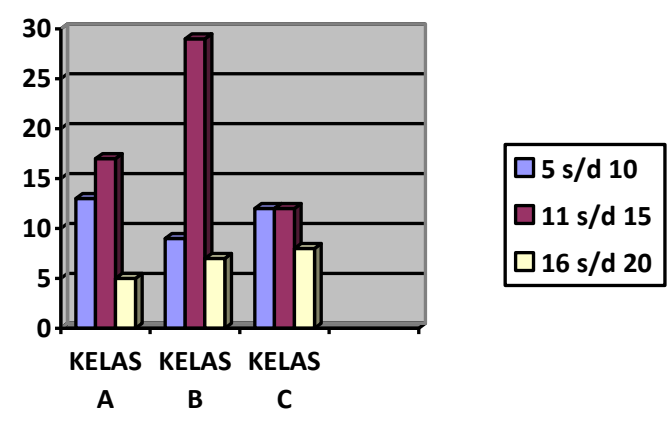

Gambar 3. Grafik Soal 3

Tabel 4. Soal 4

\begin{tabular}{cccc}
\hline Scor & Kelas A & Kelas B & Kelas C \\
\hline $\mathbf{5 - 1 0}$ & 5 & 18 & 8 \\
\hline $\mathbf{1 1 - 1 5}$ & 29 & 13 & 18 \\
\hline $\mathbf{1 5 - 2 0}$ & 1 & 4 & 6 \\
\hline TOTAL & 35 & 35 & 32 \\
\hline
\end{tabular}

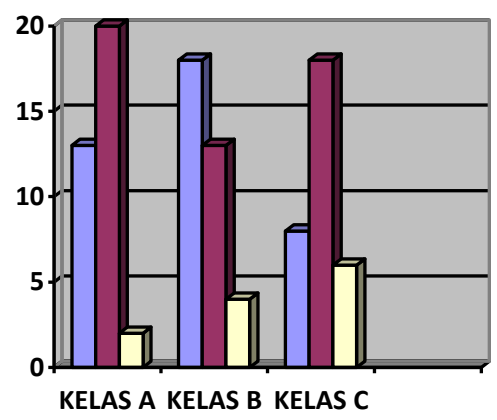

$\square 5 \mathrm{~s} / \mathrm{d} 10$ $\square 11 \mathrm{~s} / \mathrm{d} 15$

$\square 16 \mathrm{~s} / \mathrm{d} 20$

Gambar 4. Grafik Soal 4

Tabel 5. Soal 5

\begin{tabular}{cccc}
\hline Scor & Kelas A & Kelas B & Kelas C \\
\hline $\mathbf{5 - 1 0}$ & 5 & 11 & 7 \\
\hline $\mathbf{1 1 - 1 5}$ & 29 & 19 & 15 \\
\hline $\mathbf{1 5 - 2 0}$ & 1 & 5 & 10 \\
\hline TOTAL & 35 & 35 & 32
\end{tabular}

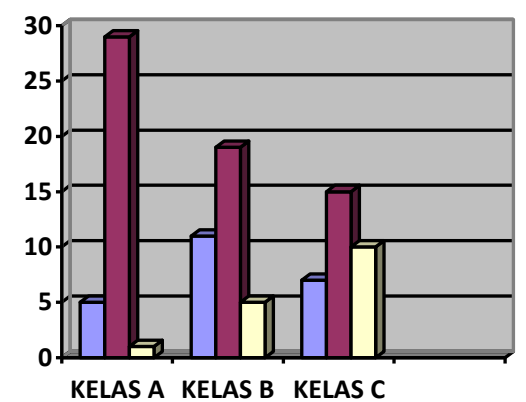

Gambar 5. Grafik Soal 5 
Penggunaan google form pun juga dapat memudahkan dosen untuk memberi skor hasil uji kompetensi dari mahasiswa, dari mahasiswa pun juga dapat mengerjakan uji kompetensi di tempat mana pun yang memiliki jaringan internet. Paparan di atas dapat dilihat bahwa penggunaan pembelajaran 4.0 berbantuan google classroom dan google form kelas rentang tertinggi di dapat oleh kelas $C$ yang disusul oleh kelas A dan Kelas B. Nilai rata-rata kelas C 76,77; rata-rata kelas A 69,71; dan rata-rata nilai kelas B 66,02.

\section{KESIMPULAN}

Perkembangan teknologi dipenggaruhi oleh perkembangan manusia. Begitu pula sebaliknya daya saing sumber daya manusia juga dipenggaruhi oleh ilmu pengetahuannya terhadap pehamahaman penmanfaatan teknologi. Pembelajaran 4.0 merupakan salah satu upaya pemerintah dalam mempersiapkan dan meningkatkan daya saing pada sumber daya manusia di dalam masyarakat dalam upaya membekali mahasiswa dalam memanfaatkan perkembangan teknologi. Saat ini jaringan internet sangat menjamur dikalanggan masyarakat. Oleh karena itu pendidik perlu lebih kreatif dalam menerapkan pembelajaran. Penerapan pembelajaran 4.0 dapat dikreasikan oleh pendidik dalam mentranfer ilmu pengetahuan.

\section{DAFTAR PUSTAKA}

Albantani \& Razak. 2018. Desain perkuliahan bahasa arab melalui google classroom. Arabiyat : Jurnal Pendidikan Bahasa Arab dan Kebahasaaraban Vol. 5 No. 1, Juni 2018, 83-102.P-ISSN: 2356-153X; E-ISSN: 2442-9473

Putri, D.G.R. 2017. Communication effectiveness of online media google classroom in supporting the teaching and learning process at civil engineering university of riau JOM FISIP Volume 4 No. 01 Februari 2017

Mertler, A. C. 2011. Action Research Improving Schools and Empowering Educators $3^{\text {th }}$ Edition (Alih Bahasa Dariyatno). Yogyakarta:Pustaka Pelajar.

Shaharanee, dkk. 2017. The Application of Google Classroom as a Tool for Teaching and Learning. Journal of Telecom-munication, Electronic and Computer Engineering. ISSN: 2180-1843 e-ISSN: 2289-8131 Vol. 8 No. 10. 
